\title{
Mud wrestling
}

I recently found myself with a few moments for reflection in the surgery, a most unfamiliar experience. The occasion was the first session of our new extended opening hours: four patients had booked appointments between 7 and 8 a.m., but only two turned up. A waste of time of course, but what a triumph for the government!

At a time when everything else he touches turns to dust, and humiliation attends every appearance of the Labour Party at the polls, Gordon Brown's imposition of supermarket hours in general practice has been a spectacular success. Although apparently bereft of the skills necessary to administer the domestic economy or a coherent foreign policy, government ministers and their spin doctors have succeeded brilliantly in convincing the nation that GPs are too busy counting their vast inflows of cash to look after their patients. Yet only the day before my dawn reverie our accountant had visited to advise us that we should anticipate a drop in real income this year.

In the same week, junior health minister Ben Bradshaw claimed that GPs were frustrating patient choice - New Labour knows no greater crime - by operating 'gentlemen's agreements' not to allow the transfer of patients from other GPs' lists. While I have no idea what goes on out in the country, I know that in inner-city London - the focus of the current reforms promoted by Lord Darzi - this allegation is preposterous. Our problem is that we have been obliged, with the greatest reluctance, to close our list to protect standards, despite the resulting financial penalties. We experience the greatest difficulty in persuading patients to register elsewhere when they have moved miles outside our practice area.

The aim behind Bradshaw's smear campaign is to prepare public opinion for his proposal to phase out the lump sum component of practice income on which many practices, including ours, are financially reliant. This campaign is driven by the prejudice that performance-linked incentives will encourage competition between surgeries and drive up standards. In reality, this policy may lead to the closure of many inner-city surgeries. Although this may facilitate the forced collectivisation of GPs in the planned polyclinics, it is unlikely either to improve standards or increase choice.

Nearly two decades ago, when he proposed the internal market, trust hospitals, and GP fundholding, Kenneth Clarke, health minister under Margaret Thatcher, pioneered the tactics for dealing with the medical profession now being ardently pursued by his Labour successors. ${ }^{1}$

Clarke later explained that his aim was to 'knock the BMA off its pedestal', to 'pull them into the mud with us' and to show the public that the professional organisation of doctors was 'just another trade union, actually one of the nastiest I had ever dealt with'. ${ }^{1}$ Although Clarke had only limited success in introducing market forces into the health service, his mudwrestling methods have proved invaluable in preparing the way for the more farreaching market reforms of the current government.

Doctors are not the only target of the anti-professional animus prevailing in British society today. A recent BBC drama provoked protests from the Bar Council over its portrayal of barristers as 'having as sound a grasp of professional ethics as Harold Shipman'. ' University lecturers, civil servants, and teachers have all suffered a loss of prestige and their professional status has been eroded by the pressures of consumerism and managerialism.

Politicians may be motivated by envy and malice in their offensive against the professions, but they too are victims of the cynical culture which they promote. Following a series of scandals about 'cash for questions', 'cash for honours', and MPs' expenses, prominent figures in all major parties have become targets of allegations of sleaze and all politicians are tainted by a public presumption of venality if not corruption. Mud-wrestling is an activity which degrades public life, demeans everybody involved, and ultimately benefits nobody.

\section{REFERENCES}

1. Timmins N. The five giants: a biography of the welfare state. London: Fontana, 1996.

2. Berlins M. TV's legal fictions don't do the profession justice. London: Guardian 2008; 30 June: http://www.guardian.co.uk/uk/2008/jun/30/law (accessed 15 Jul 2008).

DOI: 10.3399/bjgp08X319864

\section{Top Tips in 2 minutes}

What can you tell of a man by the shoes he steps out in? If possessed with the analytic prowess of Sherlock Holmes then 'a little reddish mould adhering to your instep' might be all it takes to tell that your long-suffering companion Watson has been to the Post Office on Wigmore Street where 'they have taken up the pavement and thrown up some earth, which lies in such a way that it is difficult to avoid treading in it on entering."1

As affected as such comments may now sound to our modern ear, there is much to commend the detective's ability to put together a story from careful observation of footwear.

Sometimes the story shouts out loud. The shoes in the picture below belonged to an eccentric but socially-isolated man with neuroischaemic feet who tried to accommodate the swelling from the infected ulceration of his left second and right first toe by de-lacing his shoes and adding bespoke vents with tin snips from the shed.

More often the story is more subtle, made more difficult by the injury amnesia engendered by neuropathy. However, diabetic foot lesions are not miraculous stigmata. There is always a reason to explain their appearance and the answer is often lying at your feet. If visual inspection draws a blank, run your hand carefully along the inside of the shoe worn when the injury occurred. Lost pins, coins, front door keys, and golf balls (honest!) will all be rediscovered. As Holmes explained to Watson, 'Eliminate all that is impossible, whatever remains is the explanation, however improbable.'

\section{Anthony P Coll}

\section{REFERENCE}

1. Doyle AC. The sign of four. London: Penguin classics, 2001 DOI: 10.3399/bjgp08X319882

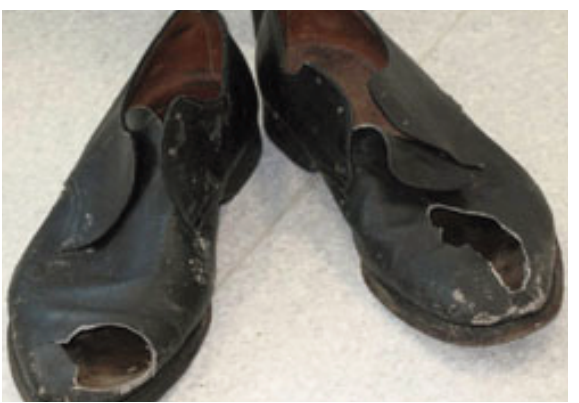




\section{Top Tips in 2 minutes: Diabetic feet.}

Why:

How:
Patients with diabetes-related foot disease have some of the longest in-patient stays; the associated comorbidities place these individuals at high risk of premature death. Many of the lesions and associated hospitalisation/amputation are avoidable with good self care, early effective management, and early referral when needed. Late referral results in early amputation.

- Many problems present without pain as a result of peripheral neuropathy. The absence of pain should NOT be taken as reassurance that there is not a serious problem.

- If problems are treated early enough, amputation can often be avoided, function can be maintained and length of stay decreased.

- Patients should have regular foot checks - annually for all and more frequently if neuropathy, peripheral vascular disease, or foot deformation.

- Monofilament testing is only part of the assessment and a patient can still have a high-risk foot even with normal perception of a monofilament.

- If a lesion is found, ask yourself why this lesion in that position on that foot? Lesions do not appear by magic and a simple history, seeing how the patient weight-bears on their foot when standing plus looking at the footwear they were (or were not!) wearing when the lesion developed can be hugely informative.

- A foot lesion can be the presenting feature of previously unrecognised diabetes.

- Always, always look at the other foot. The same risk factors (neuropathy, peripheral vascular disease, callus, poor nail care, footwear) are invariably present and often there are second lesions that the patient didn't even know they had.

What next and when:

If a lesion is found, address 5 key areas:

- Infection - This is a clinical diagnosis and a swab result will never tell you when to start antibiotics. However, swabbing open lesions before commencing antibiotics will help to ensure you've made a sensible choice - who says every bug is sensitive to flucloxacillin?

- Vascular - Are there pulses? Do not be falsely reassured by your Doppler machine. The inability to detect pulses with your fingertips is an abnormal finding and should be respected as such.

- Mechanical - Consider how you might reduce weight-bearing on the affected area.

- Metabolic - Treat hyperglycaemia aggressively.

- Social - Can the patient undertake their daily activities if they are reducing pressure on the lesion?

Remember, there is no dressing in the world that will sort out deep infection, vascular insufficiency, or severe abnormal pressure loading. If you don't know how to tackle these issues, ask someone who does.

Advise all patients:

- Good footwear is essential - have your shoes fitted.

- Check and moisturise feet daily (get someone else to do it if you can't). Refer to community podiatrist/foot protection team if neuropathy, absent pulses, callus, deformity, or other risk factor for ulceration.

Refer to the specialist foot clinic if:

- Ulceration and no foot pulses.

- Ulceration and infection/cellulitis.

- Suspected Charcot's arthropathy of the foot (hot, swollen, red foot).

- Necrosis/gangrene. Have a much lower threshold for immediate referral for anyone who has previously had an amputation and develops a new lesion.

Even when the index lesion has healed, always think 'What can I do to stop it happening again?' Many of these patients need specialised footwear and some require consideration for surgical intervention.

\section{Patient information:} http://www.patient.co.uk/showdoc/27000145/

References/Web links: Edmonds M, Foster A. Diabetic Foot ulcers. BMJ 2006; 332: 407-410 http://www.bmj.com/cgi/content/full/332/7538/407

http://www.diabetes-healthnet.ac.uk/HandBook/ScreeningOfFoot.aspx

Who are you:

Dr David Simmons (Community Diabetologist); Mrs Lucy Bishop (Senior Podiatrist); Ms Cathy Eaton (Senior Podiatrist); Dr Tony Coll (Hon Consultant Physician). The Diabetes Foot Team, Wolfson Diabetes and Endocrine Clinic, Institute of Metabolic Science, Addenbrooke's Hospital, Cambridge. 